\title{
IRRIGATION UNIFORMITY WITH COMPLETE FLUIDIC SPRINKLER IN NO-WIND CONDITIONS
}

\author{
Xingye Zhu ${ }^{*}$, Shouqi Yuan, Hong Li, Junping Liu \\ Technical and Research Center of Fluid Machinery Engineering, Jiangsu University, \\ Zhenjiang, Jiangsu Province, P.R. China 212013 \\ * Corresponding author, Address: Technical and Research Center of Fluid Machinery \\ Engineering, Jiangsu University, Zhenjiang 212013, Jiangsu Province, P.R. China, \\ Tel:+86-511-88782121,E-mail:xingye488@hotmail.com
}

Abstract: The Complete fluidic sprinkler was originally created by China. Irrigation uniformity in no-wind conditions was studied in this paper. Radial water distribution for complete fluidic sprinkler type 10 was got by experiment. MATLAB was used to establish computation program to change the radial data into net data. Three-dimensional water distribution figures for single sprinkler and combined sprinklers were figured out after the calculation of MATLAB. Combined uniformity coefficient of the complete fluidic sprinkler type 10 was simulated in combined spacing coefficient form 1 to 1.8.The maximal uniformity coefficient was $80.5 \%$ or $88.2 \%$ for rectangle or triangular combination respectively. Combined uniformity surpasses $75 \%$ when combined spacing coefficient was 1 to 1.7 in rectangle combination and 1.4 to 1.7 in triangular combination. A case study shows that the MATLAB is reliable for simulating water distribution in sprinkler irrigation.

Keywords: complete fluidic sprinkler, uniformity coefficient, combined spacing, interpolation

\section{INTRODUCTION}

Complete fluidic sprinkler is a water-saving sprinkler which is based on the wall-attachment effect. There were several modal fluidic sprinklers developed in China (Yuan et al. 2006). But the knowledge about the water

\footnotetext{
Please use the following format when citing this chapter:
} 
application of the fluidic sprinkler is quite limited. Most sprinkler irrigation systems require a minimum value of water distribution uniformity [Christiansen's Coefficient of Uniformity (CU) $\geq 80 \%$ ] (Keller and Bliesner,1990). Low values of $\mathrm{CU}$ are usually indicators of a faulty combination of the number and size of nozzles, working pressure and spacing of sprinklers. To determine Christiansen's Coefficient of Uniformity (Christiansen, 1942) and other parameters characterizing surface water distribution, we need to know the application rate caught in a grid of cans within the wetted area. The procedures to determine sprinkler water distribution can be grouped into three types: 1 . Apply the catch can grid to the existing irrigation system: evaluation of the system (Merriam and Keller, 1978; Merriam et al., 1980). 2. Place a catch can grid around a single sprinkler head in no-wind conditions and established the corresponding overlapping for any sprinkler spacing (Solomon, 1979). 3. Reduce the catch cans grid to a single-leg in a radial pattern, in no-wind and with high relative humidity conditions. The application rate can be calculated by rotating the radial pattern around the sprinkler (Vories and von Bemuth, 1986). The first procedure describes working conditions of an existing irrigation system. The second has the advantage of identifying the entire distribution pattern of the sprinkler, as well as uniformity parameters under any irrigation spacing. The third has the advantage of controlling all factors in the process, especially sprinkler water distribution, thus allowing us to establish comparisons between different sprinklers. The objective of this study was to provide an interpolation algorithm to prepare distribution maps of water depth from catch-can test data for a complete fluid sprinkler irrigation system. Uniformity parameter (CU) are then calculated from the distribution maps of application depth. This method assumes that water application depth is a continuous variable.

\section{LABORATORY PROCEDURES}

Performing the experiments in an indoor facility ensures a radial water distribution and avoids drift and losses (Sourell et al. 2003). Measurements were made in the Indoor Sprinkling Laboratory at Jiangsu University. It is a circular indoor laboratory with a diameter of $44 \mathrm{~m}$. Fig. 1 presents the condition of the laboratory. The affection of wind and other natural factors were excluded and test results were made exact and reliable. The test of point irrigated intensity is the technical sticking point and most difficult for the whole testing system. If every point is tested manually, the testing efficiency would have been low and the reliability of data would not have been as accurate. So developing an auto-testing system was an important guarantee for exploitation of new-typed sprinkler(Li 1996, Li et al. 1998). 
Jiangsu University rebuilt the testing system and changed it from a centralizing system to a total line distribution system based on the RS485. Fig.2 showed a diagram of this new testing system. The technique of using rain-collection as an implement was installed in the laboratory and connected to the computer in the control room using the RS485 assembled line. It reduced cable lengths and link workload considerably. The system was made more compact and reliable. The flow discharged from the sprinkler was determined by an auto-select system using software we had developed. Fig. 1 showed that testing points for the water were distributed radially in the testing field. The collectors were $20 \mathrm{~cm}$ in diameter and $60 \mathrm{~cm}$ high, spacing every $1 \mathrm{~m}$ and there were 40 points in all. The flow rate was measured using a flow-computer which was accurate to +_ 0.5 percent over the entire flow rate range in the irrigated room.

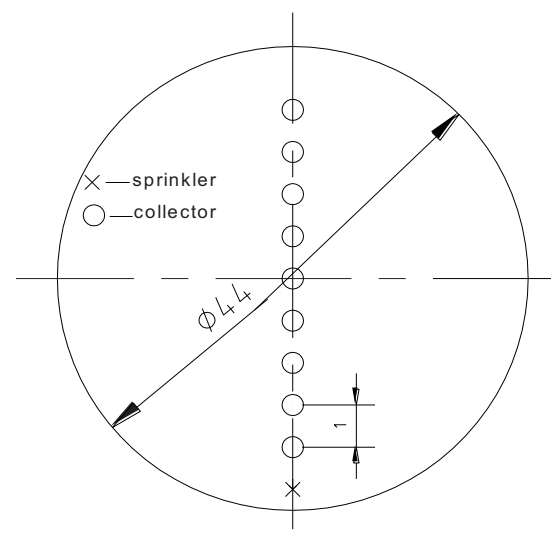

Fig.1: Testing layout for uniformity tests

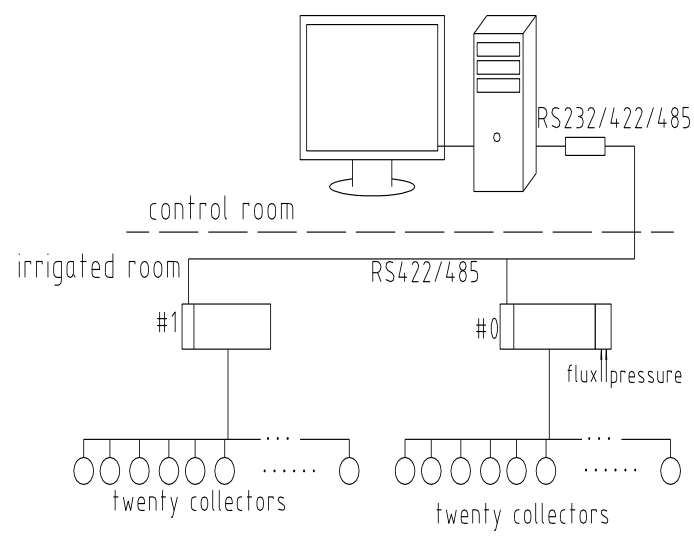

Fig.2: Auto-testing system based on total line distribution 


\section{MATHEMATICAL MODEL}

Radial data of water distribution was changed into net data for the complete fluidic sprinkler. It is the main step of analyzing uniformity coefficient and drawing three-dimensional water distribution. The water distribution can be supposed to be the same in all directions of the complete fluidic sprinkler. The depth of net point depends on the distance away from the sprinkler. It can be got using interpolation method from data that checked indeed. The model of stick insert function was established as follows:

$\mathrm{f}[\mathrm{x}]$ was supposed to be a continued function in the limited of $[\mathrm{a}, \mathrm{b}]$. Some basic points were given in $[\mathrm{a}, \mathrm{b}] . \quad \mathrm{a}=\mathrm{x} 1<\mathrm{x} 2<\ldots<\mathrm{xn}+1=\mathrm{b}$. On the assumption that $S(x)$ is a twice continuously differentiable function as:

$$
S(x)=\left\{\begin{array}{cl}
S_{1}(x) & x \in\left[x_{1}, x_{2}\right] \\
\vdots & \\
S_{i}(x) & x \in\left[x_{i}, x_{i+1}\right] \\
\vdots & \\
S_{n}(x) & x \in\left[x_{n}, x_{n+1}\right]
\end{array}\right.
$$

where $S_{i}(x)$ is a zero multinomial or a multinomial no higher than thrice $i=1,2,3, \ldots, \mathrm{n}$. They meet the condition that $S_{i}(x)=f\left(x_{j}\right)$, $j=1, \ldots, \mathrm{n}+1 . S(x)$ is the cubic spline interpolating function of $f(x)$. In that $m_{i}=S^{\prime \prime}(x), f\left(x_{i}\right)=f_{i}$ and according to the definition of cubic spline, we can get $S_{i}^{\prime \prime}(x)=m_{i} \frac{x_{i+1}-x}{h_{i}}+m_{i+1} \frac{x-x_{i}}{h_{i}} \quad x \in\left[x_{i}, x_{i+1}\right]$, where $h_{i}=x_{i+1}-x_{i}$. After twice integral of $S_{i}^{\prime \prime}(x), S_{i}(x)$ was got as follow:

$$
\begin{aligned}
& S_{i}(x)=h_{i}\left[\frac{m_{i}}{6}\left(x_{i+1}-x\right)^{3}+\frac{m_{i+1}}{6}\left(x-x_{i}\right)^{3}\right]+f_{i}+f\left[x_{i}, x_{i+1}\right]\left(x-x_{i}\right)- \\
& \frac{h_{i}^{2}}{6}\left[\left(m_{i+1}-m_{i}\right) \frac{x-x_{i}}{h_{i}}+m_{i}\right] .
\end{aligned}
$$

When ${ }^{m_{i}}$ and $m_{i+1}$ was known, the expression of $S_{i}(x)$ was wholly determined. The information of water distribution at any radial direction away from the sprinkler can be obtained after the calculation. 


\section{RESULTS AND DISCUSSION}

Water distribution is an important index of sprinkler characteristics. It is also the main gist of irrigation programming design. Tests were conducted adopting the national standards for irrigated sprinkler JB/T 7867-1997. The factors for water distribution include flow, point irrigated intensity and range under relevant pressure. Complete fluidic sprinkler type 10 was chosen in the experiments. The working pressure was $0.25 \mathrm{MPa}$ and the flow rate was $0.84 \mathrm{~m} 3 / \mathrm{h}$. Fig. 3 showed the water distributions of the sprinkler. MATLAB has a wonderful numerical calculation function. It can constitute the interpolating function and fulfill the calculation automatically. The program of drawing water distribution using MATLAB was established. Fig.4 represents the three-dimensional water distribution of this sprinkler. As can be seen from Fig.4, Water distribution of any net point around complete fluidic sprinkler can be got easily and conveniently. Water distribution by sprinkling was made more intuitionistic. It was supplied as a method expressing water distribution effectiveness more apparent.

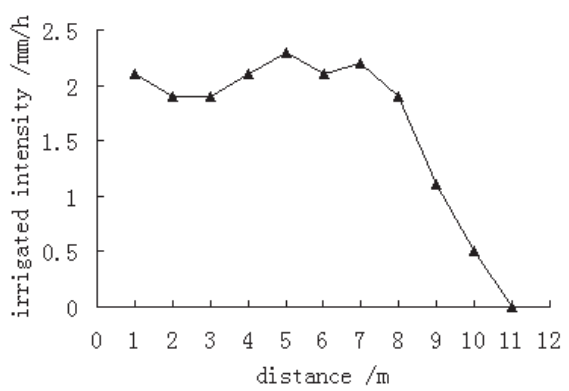

Fig.3: Water distribution of the sprinkler

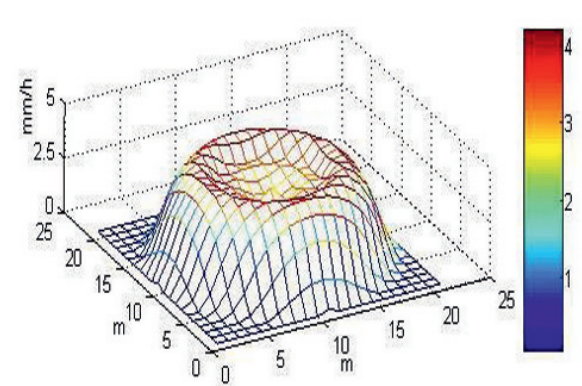

Fig.4: Three-dimensional water distribution

Double interpolation is needed to concert radial data points into grid point data (Han et al. 2007). Combined array for sprinkler in rectangular and triangular combination were discussed respectively. Fig.5 shows combined array in rectangular combination. Fig.6 shows combined array in triangular combination. As can be seen from Fig.5 and Fig.6:

$$
\begin{aligned}
& l_{m a}=\sqrt{x^{2}+y^{2}}, \quad l_{m b}=\sqrt{\left(x-r_{a}\right)^{2}+y^{2}}, \quad l_{m c}=\sqrt{\left(x-r_{a}\right)^{2}+\left(y-r_{b}\right)^{2}}, \\
& l_{m d}=\sqrt{x^{2}+\left(y-r_{b}\right)^{2}} \quad l_{m e}=\sqrt{x^{2}+y^{2}}, \quad l_{m f}=\sqrt{\left(x-r_{a}\right)^{2}+y^{2}}, \\
& l_{m g}=\sqrt{\left(x-2 r_{a}\right)^{2}+y^{2}}, \quad l_{m h}=\sqrt{\left(x-\frac{3 r_{a}}{2}\right)^{2}+\left(y-r_{b}\right)^{2}}, \\
& l_{m i}=\sqrt{\left(x-\frac{r_{a}}{2}\right)^{2}+\left(y-r_{b}\right)^{2}}
\end{aligned}
$$




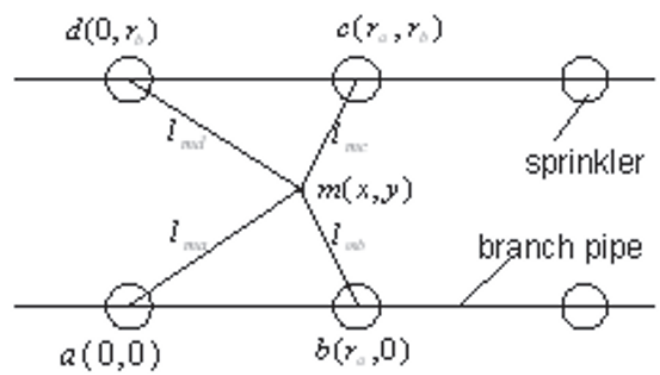

Fig.5: Combined array in rectangular combination

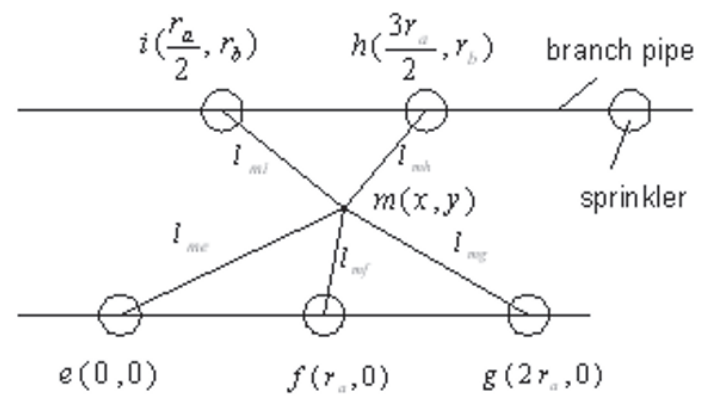

Fig.6: Combined array in triangular combination

Combined spacing interval of sprinkler was $k_{a}=\frac{r_{a}}{R}, k_{b}=\frac{r_{b}}{R}$, where $\mathrm{R}$ represents sprinkler range. While Combined spacing interval of sprinkler $k_{a}=k_{b}=1.2$, the water depth of every interpolating point was worked out using mathematical model of cubic spline interpolating. MATLAB was used to establish computation program. Fig 7 was three-dimensional water distribution of sprinkler type 10 in combined irrigation.

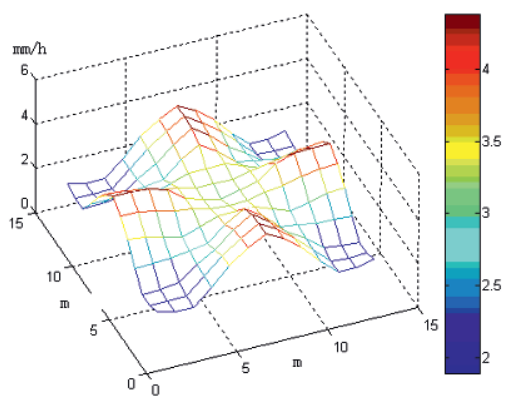

(a) rectangular combination

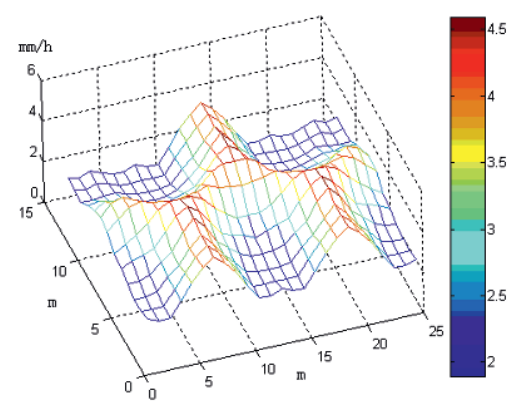

(b) triangular combination

Fig.7: Three-dimensional water distribution of sprinkler type 10 in combined irrigation

As can be seen from Fig.7, water distribution was uniform all around the irrigated control area in rectangular combination. The maximal irrigated 


\section{Conditions}

intensity was about $4 \mathrm{~mm} / \mathrm{h}$ in the middle of two sprinklers. The nearer any sprinkler was, the less water distribution of combined irrigation was. Water was triangular distribution all around the irrigated area when sprinklers work in triangular combination. The maximal irrigated intensity was about $4.5 \mathrm{~mm} / \mathrm{h}$. Combined water distributions were similar for both rectangular and triangular combination. But water distribution face was more flat for combined array in rectangular combination than combined array in triangular combination.

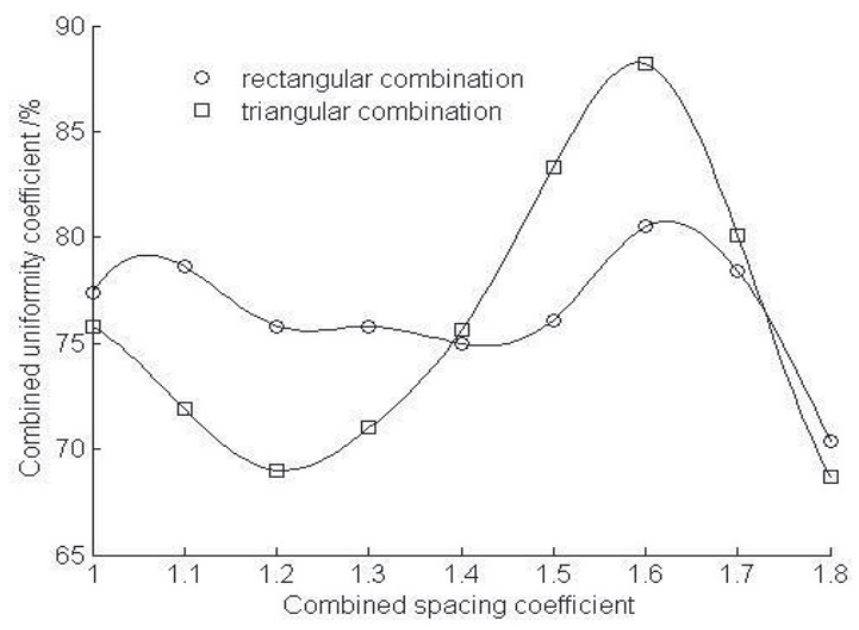

Fig.8: Simulated curves of combined irrigation coefficient

After the definition of water distribution for single sprinkler, the main factors in affecting combined irrigated uniform were combined manner and combined spacing. Under the condition that combined manner was rectangular or triangular, combined spacing coefficient $k=k_{a}=k_{b}$ was chosen by $1.1 、 1.2 、 1.3 、 1.4 、 1.5 、 1.6 、 1.7 、 1.8$ respectively. Simulation program was established. Fig. 8 was the uniformity coefficient simulated curve of combined irrigation. As can be seen from the figure, the curve of uniformity coefficient is more flat in rectangle than in triangular. It means that uniformity coefficient was stable as the change of combined spacing coefficient in rectangle combination. Uniformity coefficient changed rapidly as the change of combined spacing coefficient in triangular combination. The maximal uniformity coefficient was $80.5 \%$ or $88.2 \%$ for rectangle or triangular combination respectively. When combined spacing was 1 to 1.7 in rectangle combination and 1.4 to 1.7 in triangular combination, combined uniformity coefficient of the complete fluidic sprinkler surpasses $75 \%$, which reached the irrigated standard. 


\section{CONCLUSION}

(1) Complete fluidic sprinkler type 10 was chosen to study the irrigation uniformity in no-wind conditions. The radial water distribution was got by experiment in the Indoor Sprinkling Laboratory at Jiangsu University.

(2) Radial data of water distribution was changed into net data using cubic spline interpolating. MATLAB was used to establish computation program Three-dimensional water distribution of this sprinkler was figured out. It supplied a software platform to study the complete fluidic sprinkler.

(3) Combined array for complete fluidic sprinkler in rectangular and triangular combination was studied respectively. Combined uniformity coefficient correspond to combined spacing was simulated. The maximal uniformity coefficient was $80.5 \%$ or $88.2 \%$ for rectangle or triangular combination respectively. Combined uniformity surpasses $75 \%$ when combined spacing was 1 to 1.7 in rectangle combination and 1.4 to 1.7 in triangular combination.

\section{ACKNOWLEDGEMENTS}

Partial funding in support of this work was provided by National Hi-tech Research and Development Program of China(863 Program, No. 2006AA100211) and is gratefully appreciated.

\section{REFERENCES}

Christiansen, J.E. (1942). "Irrigation by sprinkling." Bulletin 670, California Agricultural Experiment Station, University of California, Berkeley, California.

Faci, J.M., Salvador, R., Playan, E., and Sourell, H. (2001). "Comparison of fixed and rotating spray plate sprinklers.” J. Irrig. Drain. Eng., 127(4), 224-233.

Han, W.T., Fen, H., Wu, P.T., Yang, Q., and Chen, X.W. (2007). "Evaluation of sprinkler irrigation uniformity by double interpolation using cubic splines." Effective utilization of agricultural soil \& water resources and protection of environment: 250-255.

Hendawi,M., Molle,B., Folton,C., and Granier, J. (2005). "Measurement accuracy analysis of sprinkler irrigation rainfall in relation to collector shape.” J. Irrig. Drain. Eng., 131(5), 477483.

Keller, J., and Bliesner, R.D. (1990). "Sprinkler and trickle irrigation.” New York, N.Y.: Van Nostrand Reinhold.

Li, J., and Kawano, H. (1995). "Simulating water-drop movement from noncircular sprinkler nozzles.” J. Irrig. Drain. Eng., 121(2), 152-158.

Li,J., and Hiroshi, K.,(1998). "Sprinkler performance as affected by nozzle inner contraction angle.” Irrig. Sci., 18, 63-66.

Louie, M.J., and Selker, J.S. (2000). "Sprinkler head maintenance effects on water application uniformity.” J. Irrig. Drain. Eng., 126(3), 142-148. 
Merriam, J.L., and Keller, J. (1978). "Farm irrigation system evaluation." A guide for management. Logan, Utah: Utah State University.

Merriam, J.L., Shearer, M.N., and Burt, C.M. (1980). "Evaluating irrigation system and practices." In design and operation of Farm Irrigation System, ed. M.E. Jensen, 721-760. Joseph, St., Mich.: ASAE.

Solomon, K. (1979). "Variability of sprinkler coefficient of uniformity test results." Trans ASAE, 22(5), 1078-1080, 1086.

Sourell, H., Faci, J. M., and Playán,E. (2003). "Performance of rotating spray plate sprinklers in indoor experiments.” J. Irrig. Drain. Eng., 129 (5), 376-380.

Tarjuelo, J.M., Montero, J., Valiente, M., Honrubia, F.T., and Ortiz, J. (1999). "Irrigation uniformity with medium size sprinklers. Part I: characterization of water distribution in nowind conditions." Trans ASAE, 42(3), 665-675.

Vories, E., and von Bernuth, R.D. (1986). "Single nozzle sprinkler performance in wind." Transactions of the ASAE 29(5):1325-1330.

Yuan Shouqi, Zhu Xingye, Li Hong, and Ren Zhiyuaan. (2006). "Effects of complete fluidic sprinkler on hydraulic characteristics based on some important geometrical parameters." Trans CSAE, 22(10), 113-116. (in Chinese) 